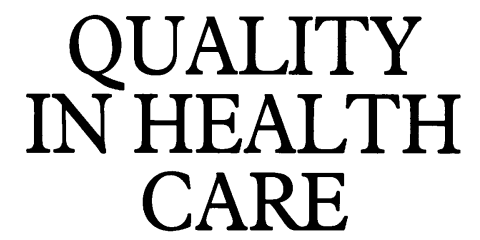

Editorial

\title{
Opportunities for improving the practice of clinical audit
}

\section{Clinical audit in the United Kingdom}

- Clinical audit, defined as "the systematic, critical analysis of the quality of clinical care," has much in common with clinical quality improvement and quality assurance in other countries

- Participation in clinical audit was made mandatory for hospital doctors in the National Health Service reforms launched by the Conservative government in 1989

- Although involvement in clinical audit remains voluntary for doctors in primary care and for other healthcare professionals such as nurses and therapists, the extent of clinical participation in audit activities is generally high

- Over $f 220 \mathrm{~m}$ of special funds has been spent on establishing an infrastructure to support clinical audit in every healthcare provider

Good clinical audit entails identifying significant problems to do with the quality of patient care; analysing their circumstances and causes; finding a solution to those problems through changes to practices, processes, or organisational arrangements; and implementing that solution to produce lasting improvements in the quality of care. Fundamentally, clinical audit is about learning from our own and others' failings, and using them positively as opportunities for improvement.

It is fitting, therefore, that those involved in clinical audit should apply the same principles to the practice of audit itself. Over the past few years, a succession of evaluative studies of clinical audit has been commissioned and undertaken in the United Kingdom, ${ }^{1}$ examining audit among doctors, ${ }^{2}$ nurses, ${ }^{3}$ and therapists ${ }^{4}$ and exploring the roles of providers, ${ }^{5}$ purchasers, ${ }^{6-8}$ royal colleges, ${ }^{9}$ regions, ${ }^{1011}$ and central government. ${ }^{12}$ Although these various studies differ in their design and scope, they all serve the same two overarching goals: to examine how effective clinical audit is in changing clinical practice and producing improvements in the quality of care and to identify ways to maximise the effectiveness of clinical audit. It can be argued that, of all the reforms to the National Health Service introduced in 1989, the development of clinical audit has perhaps been more studied, measured, and evaluated than any other. But it is not clear whether the lessons of those evaluations have been heard or heeded by those responsible for the future of clinical audit in the health service. It may help to highlight some of the most important findings and consider what actions should result from them.

\section{Acting on findings of evaluations}

Firstly, many studies suggest that success or effectiveness in clinical audit is extremely variable. In other words, while some are able to establish clinical audit activities which achieve demonstrable and worthwhile improve- ments in patient care, others struggle to do so, or fail altogether. Although the experience of failure in clinical audit is disheartening for those involved, it is no argument for abandoning audit or for not starting it in the first place. After all, the effectiveness of many clinical technologies (such as laparoscopic surgery) is very variable, especially when they are first introduced, but no one would suggest they should be discontinued. Rather, the results of evaluations should be used to understand the factors which determine whether or not clinical audit is successful, so that they can be explicitly addressed by future plans for clinical audit. There can be less and less excuse for clinical audit activities which make or repeat basic and easily avoided errors in selecting, planning, and undertaking audit projects.

Secondly, clinical audit seems from some studies to be easiest to establish in the supportive environment of a well managed organisation, in which clinicians communicate well with each other and with managers, interpersonal and organisational relationships are friendly and open, morale is good, and a common sense of purpose exists. Conversely, creating any kind of clinical audit programme is difficult in a poorly managed organisation in which discord, secrecy, rivalry, and mistrust are rife. This is a paradox, since this second organisation is almost certainly in greater need of quality improvement and will offer more opportunities to improve patient care. In other words, those who most need clinical audit may be least able to establish a successful clinical audit programme. Once again, this does not mean that clinical audit should be seen as a poor tool for improving the quality of patient care. It means that a failing audit programme may be a sign of wider organisational weakness or incapacity, and those within the organisation may be unable or unwilling to do anything about it. External pressures, from healthcare purchasers, accreditation bodies and royal colleges, are essential if the effectiveness of such audit programmes is to be improved.

Thirdly, the evaluations leave no doubt that developing clinical audit is a substantial, long term commitment which requires real support from the top levels of the healthcare provider - and a consistent and coherent corporate vision of what audit means and what it is intended to achieve. That kind of commitment has not been generally present in the National Health Service, either at the Department of Health, the NHS Executive, or among healthcare purchasers or providers. At each of these levels in the NHS, clinical audit has usually been just one priority among many, competing for managerial and clinical attention, and often losing out to more financially or politically urgent issues. Although few, if any, of these organisations will say openly that clinical audit is not really very important to them, their commitment should be judged by their actions rather than their 
words. Now that audit has shifted from being a centrally driven priority of the Department of Health to a locally determined activity for purchasers and providers to agree, there is a real danger that commitment will lessen rather than strengthen in the future.

Fourthly, the resource commitment entailed in establishing a serious clinical audit programme is substantial. About $£ 40 \mathrm{~m}$ has been spent each year for the past five years on the direct costs of clinical audit in the health service in England, such as the costs of audit staff and other support for audit activities. This sum is dwarfed by the costs of clinicians' time spent on clinical audit. If the average healthcare professional spends about an hour a week on clinical audit, that time costs about $£ 390 \mathrm{~m}$ a year. In turn, that sum may be small in comparison to the impact on healthcare costs of the changes in practice that results from audit - both cost savings and additional costs. These substantial figures have led some commentators to doubt the value of the investment and others to call for the costs and benefits of audit to be assessed. It is fair to expect that those involved in audit should measure the costs and cost consequences of each audit they undertake, so that all concerned are aware of what it has cost and what it has saved. If an effective audit programme has to demonstrate its cost effectiveness, it should not be difficult for it to do so.

Lastly, clinical audit in the health service was founded on an implicit assumption that healthcare professionals knew what it was and how to do it. The evaluations suggest that that is not the case. Clinical audit demands skills in teamwork, identifying problems, process analysis, data collection and management, problem solving, and change management - skills that are not a axiomatic part of the training for any healthcare profession. In healthcare systems outside the United Kingdom, and in industry and commerce, serious quality improvement initiatives are usually accompanied by large and ongoing training programmes. ${ }^{13}$ Many clinicians in the National Health Service have been asked to take part in clinical audit without the necessary skills or training, and the results have inevitably sometimes been disappointing to them and to others. Training and education in clinical audit need to be seen as essential for everyone taking part in audit activities.

\section{Future of clinical audit}

The past few years have been an exciting time for those involved in clinical audit in the National Health Service. We have seen more resources, time, and effort invested in clinical audit than ever before. We have shown that clinical audit can achieve remarkable improvements in patient care which are well worth the investment required. But we have also learnt, the hard way, that when clinical audit is established without proper thought and planning, it can take up a lot of time, produce little of benefit, damage morale, and make it harder to involve clinicians in any future quality improvement initiative. Our main aim, therefore, should be to replicate the former and eliminate the latter. To do that, we should heed the findings from evaluation studies, critically appraise their relevance to our own situation, and act on them if action is needed. We should also build some form of simple evaluation into all clinical audit activities, so that their performance is reviewed, progress towards objectives is measured, and their costs and benefits are assessed.

At a conference earlier this year, Don Berwick observed that, "every system is perfectly designed to get the results it gets." In other words, whether our clinical audit activities are successful or not depends largely on how successful we have designed them to be. If they are not effective in producing lasting and worthwhile improvements in the quality of patient care, the remedy lies in our own hands.

Senior Research Fellow,

KIERAN WALSHE

Health Services Management Centre,

University of Birmingham,

Birmingham B15 2RT

Walshe K, ed. Evaluating clinical audit: past lessons, futur direction London: Royal Society of Medicine, 1995.

2 Kerrison S, Packwood T, Buxton M. Medical audit: taking stock. London: King's Fund Centre, 1993

Willmot M, Foster J, Walshe K, Coles J. A review of audit activity in th nursing and therapy professions. London: CASPE Research, 1995

4 Kogan M, Redfern S, Kober A, Norman I, Packwood T, Robinson S. Clinical audit in four health professions. Uxbridge: Centre for the Evaluation of Public Policy and Practice, Brunel University, and Nursing Research Unit, Kings College London, 1995.

5 Buttery Y, Walshe K, Rumsey M, Amess M, Bennett J, Coles J. Provider audit in England: a review of twenty nine programmes. London: CASPE Research, 1995 .

6 Rumsey M, Walshe K, Bennett J, Coles J. The role of the commissioner in audit: findings of a national survey of commissioning authorities in England. London: CASPE Research, 1994

7 Lord J, Littlejohns P. Clinical audit, contracting and effectiveness: interim report. London: Health Care Evaluation Unit, St George's Hospital Medical School, 1994.

8 Exworthy M. Purchasing clinical audit: a study in the South and West Region. Southampton: Institute for Health Policy Studies, 1995.

9 Amess M, Walshe K, Shaw C, Coles J. The audit activities of the medical royal colleges and their faculties in England. London: CASPE Research. 1995.

10 Kerrison S, Packwood T, Buxton M. Review of suprahospital audit in medical specialties. Uxbridge: Health Economics Research Group,
Brunel University, 1994.

11 Foster J, Willmot M, Walshe K, Coles J. Nursing and therapy audit: a reviea of the regions' role. London: CASPE Research, 1995.

12 National Audit Office. Auditing clinical care in Scotland. London: HMSO, 1994. (HC 275.)

13 Joss R, Kogan M. Advancing quality: total quality management in the National Health Service. Buckingham: Open University Press, 1995. 